\title{
Comprehensive Evaluation of Car-Body Light-Weighting Scheme Based on LCC Theory
}

\author{
Qing-lan Han and Lan Gao \\ Accounting Department, Business School, Central South University, China
}

\begin{abstract}
In this paper, a comprehensive evaluation model of light-weighting scheme is established, which is based on three dimensions, including the life cycle costs of the resource consumed by the designed objects (LCC), willingness to pay for the environmental effect of resource consumption (WTP) and performance (P). Firstly, cost of each stage is determined. Then, based on the resource classification, which is based on cost elements, determine the material list needed, and apply WTP weight coefficient to monetize life cycle environmental impact and obtain the life cycle comprehensive cost of designed scheme (TCC). In the next step Performance (P) index is calculated to measure the value of the life cycle costs by applying AHP and SAW method, integrated (TCC) and (P) to achieve comprehensive evaluation of light-weighting scheme. Finally, the effectiveness of the evaluation model is verified by the example of car engine hood.
\end{abstract}

\section{Introduction}

On the background of sustainable development, automobile light-weighting has become a focus of academic research in the current society in which, resources and environment problems have become increasingly prominent. Light-weighting is achieved mainly through the structure improvement, material replacement and advanced manufacturing technology selection, of which the effect of material replacement is the most significant. In the designing process of lightweighting, the choice of the raw material, the corresponding production process and the connection process, have important influence on the life cycle cost, the environmental impact and the performance of the lightweight scheme. The usage of a large number of cars has caused a lot of problems such as energy shortage and environmental pollution to human society. Therefore, from the perspective of LCC, research on how to reduce the life cycle cost and environmental impact of automotive products, and improve the product life cycle performance, so as to guide the selection of lightweighting designation program is of great significance.

Study on the comprehensive evaluation of light quantization schemes abroad: Ine`s Ribeiro, Paulo Pec, as etc. [1], integrated LCA, LCC considering the material properties, to analyze the life cycle costs and environment impact of low carbon steel, high strength steel, and Aluminum Alloy, in order to provide selection concerning car fender material replacement and material selection. Robert A. Witik, Jérôme Payet etc. [2] analyzed the life cycle costs and environmental impact of 6 different materials used for replacing car boot partition, based on the theory of LCC and LCA, to obtain the comprehensive evaluation value. While Ahmad $T$. Mayyas etc. [3], proposed designation oriented for life cycle assessment, as ecological designation decision support tools used for optimization design and lightweight material selection for white car bodies. Domestic literature Lv Yining, Lv Zhenhua [4], by setting the thin wall plate structure rigidity for objective, proposed that body sheet bending strain energy and membrane strain energy can be considered as performance evaluation, so as to guide the lightweighting scheme evaluation and selection, but they did not consider the cost and environmental impact of each scheme. Li Yanping, Liu Haijiang etc. [5] set the goal of reducing costs and weight and improving performance, put forward that light-weighting scheme evaluation should be based on multi-objective decision satisfaction mechanism, by verifying car engine hood. Han Qinglan, Zhang Yang etc. [6] applied light-weighting material as the main input variables, using AHP method to establish the LCC and LCA integrated evaluation model, at the same time, put the model into the car door material selection case.

Though scanning domestic and foreign literature, it is not difficult to find that foreign literature focuses on the life cycle assessment of light-weighting materials, domestic literatures focus on light-weighting designation method research, however, few are based on LCC perspective for comprehensive quantitative evaluation of light-weighting design. Taking this as the breakthrough point, this paper builds a comprehensive evaluation model of light-weighting program from three dimensions 
of economy, environment and performance from the perspective of LCC.

\section{Comprehensive evaluation model of lightweight scheme}

In this paper, the light-weighting designation is mainly considered upon the selection of light-weighting materials and the use of advanced technology. The life cycle cost, environmental impact and performance of the scheme are different because of different materials and processes. Therefore, in order to evaluate the scheme comprehensively, above factors must be fully considered from the perspective of LCC. Comprehensive evaluation model is shown in Fig. 1:

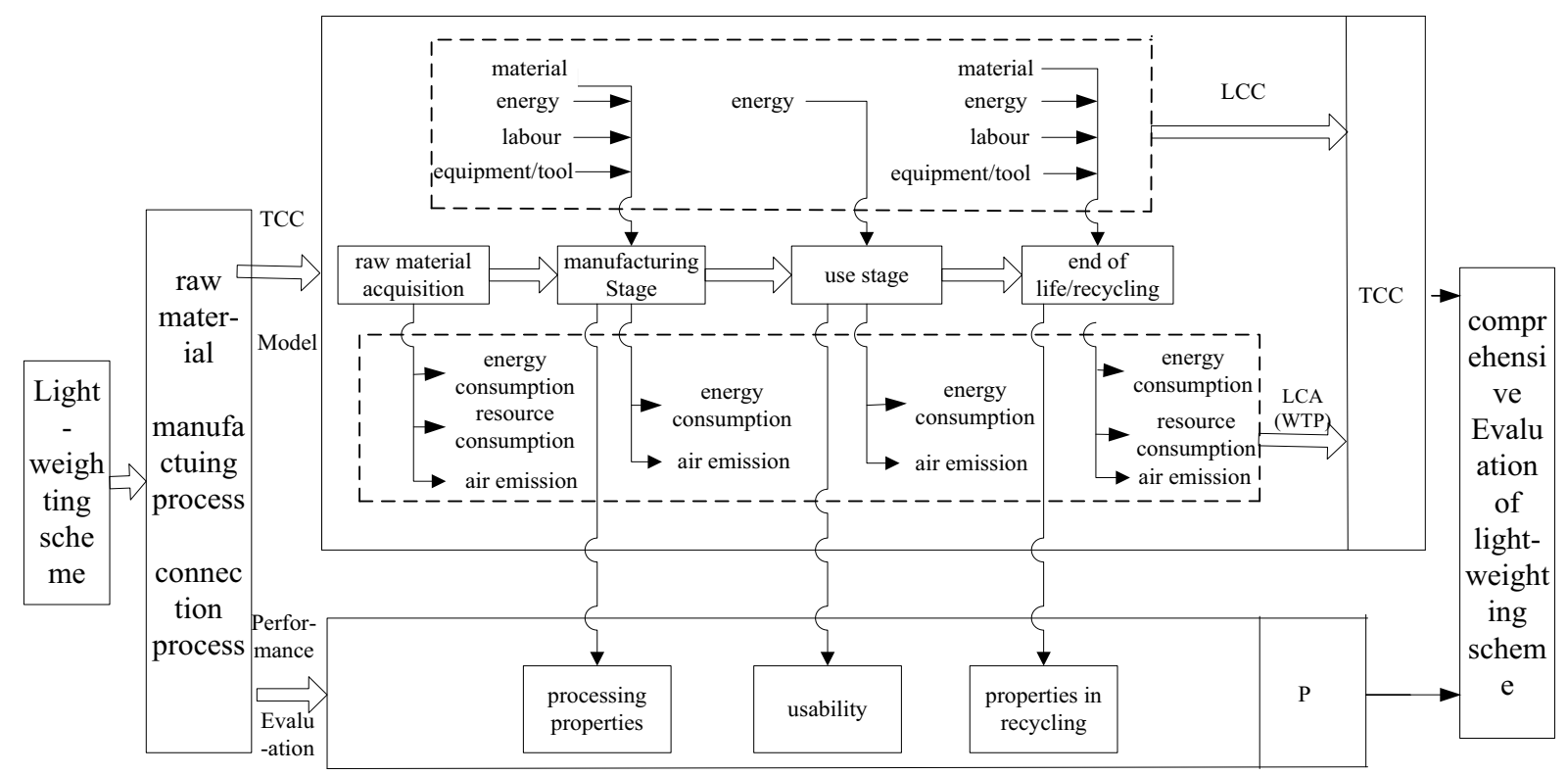

Figure 1. Comprehensive evaluation model of light weight scheme.

Evaluation scope includes raw material acquisition stage, manufacturing stage, usage stage and recovery stage. The input-output model based on process, the elements put into each stage of the life cycle such as materials, energy, labour, equipment and other costs are main data to compute LCC while environmental factors generated by the consumption of resources at each stage of the life cycle are main data used for the LCA detailed list analysis. Monetizing LCA to achieve the integration of LCC and LCA so that a comprehensive cost of lightweighting program can be achieved. Then, evaluate performance within manufacturing process, usage process and recovery phase using AHP and SAW methods to get the performance value. Finally, integrate comprehensive cost and performance value to obtain the comprehensive quantitative evaluation of the light-weighting scheme

\subsection{Life cycle cost model}

The life cycle cost relates to different life cycle stages, so establishing cost model based on process ac-cording to input-output model is needed. Input factors are divided into material cost $C_{M}$ labor cost $C_{L}$ energy cost $C_{E}$ equipment and tools $C_{T / E}$ calculate the cost of each process, as shown in the formula (1):

$$
C_{P}=C_{M}+C_{L}+C_{E}+C_{T / E}
$$

The calculation formula of each input element in the process model is (2)-(5):

$$
C_{M}=\sum_{i=1}^{I} w_{i} \cdot P_{i} \cdot\left(1+r_{i}\right)
$$

$w_{i}, P_{i}, r_{i}$ represent material quantity, unit price and scrap rate

$$
C_{L}=\sum_{k=1}^{n} P_{k} \cdot t_{k} \cdot n_{k}
$$

$P_{k}, t_{k}, n_{k}$ represent reward per unit time, working hours and the number of workers in the $\mathrm{k}$ process.

$$
C_{E}=\sum_{n=1}^{N} E_{n} \cdot P_{n}
$$

$E_{n}, P_{n}$ represent of energy consumed in the nth energy and the price per unit of energy. represent material quantity, unit price and scrap rate.

$$
C_{T / E}=\sum_{m=1}^{M} I_{m} \cdot r \cdot(1+r)^{m n} /((1+r)-1) T / U T
$$

$I_{m}, m n, T, U T$ represent The cost of investment, investment return rate, the payback period of the $m$ th investment, the running time of the year, the total service life of them. 


$$
L C C=w_{p} \cdot C_{P P}+w_{U} \cdot C_{P U}+w_{R} \cdot C_{R R}
$$

$C_{P P}, C_{P U}, C_{R R}$ represent the cost of manufacturing phase, usage phase and recovery phase, $w_{P}, w_{U}, w_{R}$ represent the weight of manufacturing phase, usage phase and recovery phase.

\subsection{Assessment model of life cycle environmental impact}

Currently, carbon footprint and LCA method are most frequently applied to value the environmental impact, of which LCA applies more EI99 to quantify. In this paper, based on the LCA method, environmental impact is monetized by applying WTP weighted index and then incorporated into the comprehensive life cycle cost. Specific steps are as follows:

Classification: analyze detailed data to classify various factors as types.

Characterization: convert factors $Q_{i}$ into influencing outcomes with unified units. Then, through totalling influencing value is achieved which can reflect the environmental impact. The formula is as follows:

$$
S_{k}=\sum_{i=1}^{I} Q_{i} \cdot E P_{i}
$$

$Q_{i}$, stands for the analysis measurement of each unit per function releasing $i, E P_{i}$ is the equivalent factor.

Weight processing: $S_{k}$ characterized and the coefficient of willingness to pay, $V_{k}$ are processed together, to get $W T P_{k}$ to achieve the goal to monetize WTP, the formula is:

$$
W T P=\sum_{k=1}^{K} S_{K} \cdot V_{k}
$$

\subsection{Life cycle performance evaluation model}

Firstly, determine the performance evaluation index of each stage. Secondly, collect data to get the attribute value of each index and make the qualitative index quantitative. Then, normalize the index value by mathematical transformation. Finally, performance values are obtained by using AHP method and SAW method. The calculation formula is as follows:

$$
P_{i}=\sum_{j=1}^{J} w_{j} \cdot m n_{i j}
$$

$P_{i}, w_{j}$ represent performance value, weight of scheme i $(\mathrm{i}=1,2, \ldots, \mathrm{N}), \mathrm{m}_{\mathrm{ij}}$ represent the attribute value of $\mathrm{j}(\mathrm{j}=1,2,3 \ldots, \mathrm{J})$ of scheme

$$
P_{i}=\sum_{j=1}^{J}=w_{j} \cdot m_{i j n o r m}
$$

Efficiency index standardization

$$
m_{i j n o r m}=\frac{m_{i j}}{\max \left[m_{i j}\right]_{1}^{N}}
$$

Cost index standardization

$$
m_{i j n o r m}=\frac{\min \left[m_{i j}\right]_{1}^{N}}{m_{i j}}
$$

\subsection{Comprehensive evaluation model}

The output of TCC that integrated economy and environment is cost, however, the result of life cycle performance evaluation is non-dimensional value. To realize the integration of the two, the standardization of TCC is needed. The formulation is as follows:

$$
T C C_{\text {knorm }}^{\prime}=\frac{\min [T C C]_{1}^{N}}{T C C_{k}}
$$

Formula (14) is used to get the comprehensive evaluation value of total life cycle cost, environment and performance.

$$
\text { Value }_{k}=P_{k} / \text { TCC }^{\prime}{ }_{k n o r m}
$$

\section{Model application}

In this paper, engine hood is used as example to evaluate light-weighting. According to literature [7], 3 types of designation plan can be seen as Table 1: includes inner $\mathrm{p}$.

Table 1. Light-weighting scheme of engine hoods.

\begin{tabular}{|c|c|c|c|}
\hline Scheme & Scheme 1 & Scheme 2 & Scheme 3 \\
\hline Outer plate & $0.75 \mathrm{~mm}$ strengthened steel & $1.50 \mathrm{~mm}$ aluminum alloy & $1.5 \mathrm{~mm}$ aluminum alloy \\
Inner plate & $0.60 \mathrm{~mm}$ strengthened steel & $0.75 \mathrm{~mm}$ strengthened steel & 1.5 mm aluminum alloy \\
\hline Connection type & Flanging, rolling depression, splice & Flanging, rolling depression, splice & $\begin{array}{c}\text { Flanging rolling } \\
\text { depression, splice }\end{array}$ \\
\hline $\begin{array}{c}\text { Manufacturing } \\
\text { process }\end{array}$ & hydraumatic & $\begin{array}{c}\text { Aluminum/stamping, strengthened } \\
\text { steel/hydraumatic }\end{array}$ & stamping \\
\hline
\end{tabular}

Table 2. Cost of each phase.

\begin{tabular}{|c|c|c|c|c|}
\hline Scheme & $\begin{array}{c}\text { manufacturing phase/[\$] } \\
\left(w_{P}=0.64\right)\end{array}$ & $\begin{array}{c}\text { Use phase } /[\$] \\
\left(w_{U}=0.28\right)\end{array}$ & $\begin{array}{c}\text { Recovery phase/[\$] } \\
\left(w_{R}=0.07\right)\end{array}$ & Total cost/[\$] \\
\hline Scheme 1 & 50.39 & 133.42 & -0.33 & 69.58 \\
\hline Scheme 2 & 60.01 & 128.18 & -5.45 & 73.92 \\
\hline Scheme 3 & 74.32 & 107.26 & -9.68 & 76.92 \\
\hline
\end{tabular}




\subsection{Life cycle cost estimation}

\subsubsection{Cost estimation in manufacturing phase}

Material cost is obtained based on data collected and formula (2) based on manufacturing, connection characteristics of each scheme, equipment costs mainly consist of molds costs and fashioned equipment costs. Therefore, labor costs, energy costs, equipment costs and total costs can be calculated based on data collected and formula (3) (4) (5) (1).

\subsubsection{Use phase cost estimate}

The main cost is the cost of fuel consumption and maintenance in this stage, According to the literature [6], automobile fuel consumption and weight are highly correlated. Consumption of gasoline will in-crease $0.004 \mathrm{~L}$ when weight of each car traveling 100 kilometers increases by 1 kilogram. Therefore, this paper only considers the cost of fuel consumption, i.e. energy cost, which is directly related to the de-sign scheme. Assuming that the mileage during life cycle of a car is 25 million kilometers, 93 gasoline price was $133.42 \$ / \mathrm{L}$

\subsubsection{Cost estimation within recovery phase}

This stage mainly considers the equipment cost, energy cost and labor cost involved in dismantling and recycling activities. Cost of raw materials is the in-come of recycled materials. Assume that the recovery rates of highly strengthened steel and aluminum alloy were $85 \%$ and $95 \%$, respectively. The price of aluminum scrap and steel scrap are is $1.1 \$ / \mathrm{kg}$ and $0.12 \$ / \mathrm{kg}$. Therefore, cost within the recovery stage is calculated through formula (2) - (5).

As costs incurred during each stage of the life cycle belong to different subjects, designers consider the manufacturing costs as well as costs incurred within usage stage and recycle stage from the perspective of company interest. As a result, weight is needed to value different stages in the life cycle, this paper adopts weight data from literature [7] which sets manufacturing as 0.64 , usage as 0.28 and recycling as 0.07 , to get the LCC of different scheme through formula (6) The cost of different phase show in Table 2.

\subsection{Life cycle environmental impact}

By using the collected data, and considering the influence of producing $1 \mathrm{~kg}$ steel and aluminum on the environment, the detailed list of raw material data in acquisition stage. [8], [9] can be calculated, as well as the detailed list data of manufacturing phase through consumption and unit emission of oil, coal and electricity. Index of environmental impact in using phase is determined by data of use stage and environmental impact of unit oil consumption amount. In recovery phase, improvement of environment brought by resource and energy conservations of material recycling is mainly considered. Finally, on the basis of materials and processes in all schemes, environmental impact data in all phases of the life cycle are determined

The characteristic factor is obtained through the research of existing references. According to domes-tic air emission, resource and energy consumption, the resource tax rate as well as the reference document [10], [11], a list of social-willingness-to-pay is obtained $\mathrm{CO}_{2}$ is $3.4 \mathrm{E}-02$, NOx is $1.39 \mathrm{E}-01, \mathrm{SO} 2$ is $9.74 \mathrm{E}-02$, petroleum is $0.98 \mathrm{E}-03$, coal is $8.40 \mathrm{E}-03$, Ironore is $1.71 \mathrm{E}-$ 02.According to the composition of electricity in China, electric energy can be converted into the consumption of coal, and $1 \mathrm{KWh}$ electricity $=0.424 \mathrm{~kg}$ Coal [12], assuming that gasoline consumption is equivalent to petroleum consumption. According to the formula (7) and (8), the life cycle environment impact in each scheme is obtained, as shown in Table 3:

Table 3. Life cycle environment impact in each scheme.

\begin{tabular}{|c|c|c|c|c|c|}
\hline Scheme & $\begin{array}{c}\text { Raw materials } \\
\text { acquisition phase }\end{array}$ & Manufacturing phase & Using phase & Recovery phase & WTP/ [\$] \\
\hline 1 & 1.52 & 0.77 & 10.79 & -0.86 & 12.22 \\
\hline 2 & 3.17 & 1.07 & 10.36 & -1.94 & 12.66 \\
\hline 3 & 4.37 & 1.23 & 8.67 & -2.74 & 11.53 \\
\hline
\end{tabular}

Table 4. Life cycle performance values of each scheme.

\begin{tabular}{|c|c|c|c|c|c|c|c|c|c|}
\hline \multirow{4}{*}{ Scheme } & \multirow{4}{*}{$\frac{B_{j}}{w_{j}}$} & \multicolumn{8}{|c|}{ Index } \\
\hline & & \multicolumn{3}{|c|}{ The manufacturing phase } & \multicolumn{3}{|c|}{ The using phase } & \multirow{2}{*}{$\begin{array}{c}\text { The recovery phase } \\
\text { Recovery rate }\end{array}$} & \multirow{3}{*}{$P_{i}$} \\
\hline & & Feasibility & Complexity & Productivity & Rigidity & Modal & Weight & & \\
\hline & & & 0.08 & 0.05 & 0.36 & 0.21 & 0.08 & 0.07 & \\
\hline \multicolumn{2}{|l|}{1} & 0.42 & 1 & 0.33 & 1 & 0.87 & 0.80 & 0.89 & 0.82 \\
\hline \multicolumn{2}{|l|}{2} & 0.71 & 0.6 & 0.55 & 0.74 & 0.78 & 0.84 & 0.94 & 0.74 \\
\hline \multicolumn{2}{|l|}{3} & 1 & 0.42 & 0.78 & 0.33 & 1 & 1 & 1 & 0.69 \\
\hline
\end{tabular}


Table 5. The comprehensive evaluation values of each scheme in life cycle.

\begin{tabular}{|c|c|c|c|c|c|c|}
\hline Scheme & LCC/[\$] & WTP/[\$] & TCC/[\$] & Standardization & P & P/TCC (Value) \\
\hline 1 & 69.58 & 12.22 & 81.80 & 1 & 0.82 & 0.82 \\
\hline 2 & 73.92 & 12.66 & 86.58 & 0.94 & 0.74 & 0.79 \\
\hline 3 & 76.92 & 11.53 & 88.45 & 0.92 & 0.69 & 0.75 \\
\hline
\end{tabular}

\subsection{Life cycle performance evaluation}

As a closure member of car-body, engine hood is designed to protect the engine, so that the rigidity and strength affect crashworthiness directly. The weight directly influences fuel costs in using process. The modal reflects vibration reducing performance of cars. Therefore, rigidity, first-order modal and weight are selected as performance evaluation indexes in using process.

While light-weighting scheme is being designed performance of manufacture process and recovery process, as well as performance of products using phase are all considered. As a consequence, in this paper, the feasibility, complexity and productivity of the process are selected as the evaluation indexes of the process performance in the manufacturing stage, and the recovery rate as the evaluation index of the ending stage. Based on the existing references, expert advice and the 5 Component [13], the manufacturing index values are determined.

It is different of the importance of each stage in the product life cycle. It is also different of the importance each performance index counted in each stage. In this paper, the AHP method is applied to determine the weight of each stage of the life cycle and the weight of each performance index counted in each stage. So as to determine the weights of manufacturing stage, use stage and recovery stage were $0.27,0.65$ and 0.07 .

Using the same method, the weight of feasibility, the complexity and the productivity in the manufacturing stage are determined as $0.53,0.3$ and 0.17 . The weights of rigidity, modal and weight in using stage are $0.56,0.32$ and 0.12 . Since only one index is chosen in recovery phase, the weight is 1 . After standardization of the performance values in all phases by using formula (11) and (12), and calculation of weight of life cycle indexes by using formula (10), performance values of each scheme are as shown in Table 4.

\subsection{Comprehensive evaluation}

TCC of each scheme is obtained by totaling LCC and WTP, and standardized TCC is got by formula (13). Then by integrating $\mathrm{P}$ with formula (14), life cycle comprehensive evaluation value of all schemes have been obtained, as shown in Table 5.

In summary, with consideration of material and process, and based on the perspective of LCC, 3 lightweighting schemes are evaluated comprehensively from three dimensions -economics, environment and performance. The best one is program 1, which can be seen in Table 5.

\section{Conclusions}

This paper, based on LCC theory, and from the perspective of the resource-based view, analyzes resource consumptions of the designed object in each stage of the life cycle, and the environmental impacts caused by resource consumptions. Meanwhile, this paper takes into account the performance factor of the designed object, and constructs light-weighting design synthetic evaluation model. On the basis of this model, this paper establishes the life cycle cost model, the environmental impact assessment model and the product performance evaluation model. According to the consumption of each stage, the calculation formula, the calculation process and the solving method of each model are provided

Then, taking three design schemes of the automobile engine hood as examples, the material cost, manufacturing cost, consumption cost and recovery cost are first calculated by using the cost model. Then, the BOM that impacts environment is determined according to the cost of each stage. Besides, by using environmental impacts evaluation model, environmental impacts in each stage are monetarily measured, so as to realize the unification of two measurement standards. In the end, by applying the performance evaluation model, the performance indexes are calculated in 3 stages - hood manufacturing, usage and recovery stages. By means of AHP method, the weights of life cycle stages and performances indexes are determined, which comes to the only value $(\mathrm{P})$ of metric properties, and realization of quantitative unification of the three dimensions of the comprehensive evaluation model. Then, the fuzziness of the qualitative evaluation is solved.

Finally, the validity and feasibility of the model are proved by an example, and proved to be applicable for wider use.

\section{Acknowledgement}

This paper was financially supported by the National Natural Science Foundation(71172101).The project is Building and Application Knowledge base with Theory of Life Cycle Cost.

\section{References}

1. I. Ribeiro, Paulo Pec etc., Journal of Cleaner Production, 16, 1887-1899 (2008) 
2. R. A. Witik, J. Payet, Composites Part A: Applied Science and Manufacturing. 42, 1694-1709 (2011)

3. A. T. Mayyas, A. Qattawi, Energy, 39, 412-425 (2012)

4. L. Ying-ning, L. Zhen-hua, Journal of Mechanical Engineering, no. 12, 289-294 (2009)

5. L. Yan-ping, L. Hai-jiang T. Rong-hui, Computer Integrated Manufacturing Systems, no. 01, 37-44 (2011)

6. H. Qing-lan, Z. Yang, Science and Technology Management Research. 7. 180-184 (2015)

7. W. Hong-yan, G. Wei-ming, Journal of Tong Ji U (Nature Science), vol. 43, no. 8, 1098-1103 (2006)

8. L. Zhen, Research on Environmental Consciousness Design and Evaluation Method of Electromechanical Products, (2013).
9. W. Shuai, Reserch on the EIA of Read-mixed concrete during the life cycle, (2009)

10. C. Wei-qiang, W Hong-yan, W. Juan-ni etc., (2009). Light Metal, 5. 2-10 (2009)

11. L. Zhi-chao, Life Cycle Assessment Meth-odology of Original Manufacturing and Remanu-facturing of an Engine, (2013)

12. Liu S N, Lin Z S, Zhang X W, China Environmental Science, 18, 328-332

13. Chen SJ, Hwang, Lecture notes in economics and Mathe-matical systems, Springer, (1992)

14. L. Shi-hui, H. Qing-lan, Accounting Research, 7, 35$42(2013)$ 